\title{
DIAGNÓSTICO DE ENFERMAGEM TENSÃO DO PAPEL DE CUIDADOR EM FAMILIARES DE PESSOAS COM FERIDAS CRÔNICAS
}

Nursing diagnosis tension of the role of caregiver in family members of people with chronic wounds

Diagnóstico de enfermeira tensión del papel del cuidador en los familiares de personas con heridas crónicas

Kezia Juliana da Silva ${ }^{1}$, Julliany Lopes Dias ${ }^{2}$, Maurício Gomes da Silva Neto ${ }^{3}$, Henrique da Silva Oliveira Araújo ${ }^{4}$, Amanda Martins Bastos ${ }^{5}$, Marlene Andrade Martins ${ }^{6}$, Selma Rodrigues Alves Montefusco ${ }^{7}$, Ângela Lima Pereira $^{2 *}$.

${ }^{1}$ Graduada em Enfermagem pela Universidade Federal do Tocantins, Palmas, Tocantins, Brasil.

${ }^{2}$ Professora do Curso de Enfermagem da Universidade Federal do Tocantins, Palmas, Tocantins, Brasil.

${ }^{3}$ Enfermeiro da Unidade Básica de Saúde Dr. Otto Carneiro Maciel, Jataí, Goiás, Brasil.

${ }^{4}$ Enfermeiro do Hospital Urológico, Palmas, Tocantins, Brasil.

${ }^{5}$ Enfermeira, Palmas, Tocantins, Brasil.

${ }^{6}$ Professora do Curso de Enfermagem da Universidade Federal de Jataí, Jataí, Goiás, Brasil.

${ }^{7}$ Professora da Faculdade de Enfermagem da Universidade Federal de Goiás, Goiânia, Goiás, Brasil.

*Correspondência: Grupo de Estudo e Pesquisa sobre Feridas (GEPF), Universidade Federal do Tocantins (UFT), Av. NS 15, 109 Norte, Palmas, Tocantins, Brasil. CEP:77.010-090. e-mail angelimap@uft.edu.br.

Artigo recebido em 24/10/2019 aprovado em 27/05/2020 publicado em 29/08/2020.

\section{RESUMO}

O cuidado da pessoa com ferida crônica é complexo, e sob responsabilidade da família gera demandas que podem resultar em cansaço e desgaste do cuidador, que é apresentado na NANDA-I como tensão no papel de cuidador. O objetivo foi verificar a ocorrência do diagnóstico de enfermagem (DE) tensão do papel de cuidador em familiares de pessoas com feridas crônicas. Trata-se de um estudo descritivo exploratório, realizado em 2019, por meio de entrevista semiestruturada com pessoas que cuidam de um familiar com ferida crônica em Palmas-Tocantins. Análise de variáveis quantitativas realizada por estatística descritiva, e de variáveis subjetivas por "agrupamento de dados" e “interpretação do agrupamento". Identificados 6 cuidadores com DE tensão no papel de cuidador, com predomínio do sexo feminino, grau de parentesco de filhos e cônjuges. Os principais fatores relacionados foram: excesso de atividades de cuidado, crise financeira e o prejuízo à saúde. A principal característica definidora foi a falta de tempo para atender às necessidades pessoais. Tensão no papel de cuidador em familiares de pessoas com feridas crônicas gera implicações significativas na saúde e dinâmica de vida dos cuidadores. Assim, tornam-se necessárias políticas de saúde que atendam não apenas a população com ferida crônica, mas também a família.

Palavras-chave: Relações familiares; Diagnóstico de Enfermagem; Cuidadores.

\section{ABSTRACT}

The care of the person with chronic wound is complex, and under the responsibility of the family generates demands that can result in tiredness and weariness of the caregiver that is presented at NANDA as tension in the role of caregiver. The objective was to verify the occurrence of nursing diagnosis (ND) tension of the role of caregiver in family members of people with chronic wounds. It is an exploratory descriptive study, held in 2019, through semi- 
structured interviews with people who care for a family member with chronic wound in Palmas-Tocantins. Analysis of quantitative variables performed by descriptive statistics, and subjective variables by "data grouping" and "grouping interpretation". Identified 6 caregivers with ND tension of the role of caregiver, with a predominance of females, kinship of children and spouses. The main related factors were: excessive care activities, financial crisis and health impairment. The defining characteristic was the "lack of time to meet personal needs". Tension in the role of caregiver in family members of people with chronic wounds generates significant implications for caregivers' health and life dynamics. Thus, health policies are needed that address not only the population with chronic wound, but also the family.

Keywords: Family Relations; Nursing diagnosis; Caregivers.

\section{RESUMEN}

El cuidado de la persona con herida crónica es complejo y, bajo la responsabilidad de la familia, genera demandas que pueden resultar en cansancio y agotamiento del cuidador que se presenta en NANDA como tensión en el papel del cuidador. El objetivo fue cheque la ocurrencia del diagnóstico de enfermería (DE) tensión del papel del cuidador en los familiares de personas con heridas crónicas. Este es un estudio exploratorio descriptivo, realizado en 2019, a través de entrevistas semiestructuradas con personas que cuidan a un familiar con heridas crónicas en PalmasTocantins. Análisis de variables cuantitativas realizado por estadística descriptiva y variables subjetivas por "agrupación de datos" e "interpretación de agrupación". Se identificaron 6 cuidadores con DE con tensión en el papel de cuidador, con predominio de las mujeres, parentesco de niños y cónyuges. Los principales factores relacionados fueron: actividades de atención excesiva, crisis financiera y deterioro de la salud. La característica definitoria era la "falta de tiempo para satisfacer las necesidades personales". La tensión en el papel del cuidador en los familiares de personas con heridas crónicas genera importantes implicaciones para la salud y la dinámica de la vida de los cuidadores. Por lo tanto, se necesitan políticas de salud que aborden no solo a la población con heridas crónicas, sino también a la familia.

Palabras clave: Relaciones familiares; Diagnóstico de Enfermería; Cuidadores.

\section{INTRODUÇÃO}

No processo de cuidar da pessoa - indivíduo, família ou comunidade, segundo Hickman (2000), o enfermeiro necessita identificar as demandas de cuidado que devem ser satisfeitas, sejam estas relacionadas a um problema de saúde, estados de vulnerabilidade ou disposição para a promoção da saúde. Esse é um processo complexo que envolve a coleta de dados de informações acerca da pessoa que é o objeto do cuidado, e o raciocínio clínico específico de enfermagem que culminará na identificação do diagnóstico de enfermagem (NANDA - I, 2018).

Diagnóstico de enfermagem é um "julgamento clínico sobre uma resposta humana a condições de saúde/processos de vida, ou uma vulnerabilidade a tal resposta, de um indivíduo, uma família, um grupo ou uma comunidade" (NANDA - I, 2018).

A declaração diagnóstica apresenta uma estrutura padronizada, composta por um título ou termo diagnóstico, e seus indicadores, que são os fatores relacionados e as características definidoras. Os fatores relacionados constituem a etiologia, causa ou fator contribuinte para aquela resposta humana, enquanto as características definidoras são as inferências ou sinais observáveis na pessoa. Quando se trata de um diagnóstico de risco, esses indicadores são expressos como fatores de risco, ou seja, os sinais que indicam o estado de vulnerabilidade (NANDA - I, 2018; CRAVEN; HIRNLE, 2006).

O diagnóstico de enfermagem da NANDAInternacional (NANDA-I), em sua última edição, apresentou na composição de um diagnóstico mais duas categorias, a saber: populações em risco e condições associadas, que antes eram elencados dentro dos fatores relacionados/de risco, porém não eram passíveis de intervenções de enfermagem, por isso sua separação em novas categorias (NANDA - I, 2018). 
De maneira geral, desvios de saúde, sejam agudos ou crônicos, têm sido apontados como estressores que geram sofrimento não apenas na pessoa enferma, mas também na família. A cronicidade certamente amplia essa problemática, podendo gerar diversas respostas humanas no cuidador, causando inclusive seu adoecimento (PEIXOTO; BORGES, 2011; MONTEFUSCO et al., 2011).

Feridas crônicas são consideradas um problema de saúde pública, tendo impacto econômico e social no mundo todo, para o sistema de saúde, para o paciente e para a família do indivíduo que possui a ferida, especialmente quando o familiar também se torna o cuidador principal (LEAL et al., 2017); entre os problemas enfrentados pelo familiar cuidador, pode-se citar a tensão no papel de cuidador.

A Taxonomia de Diagnósticos de Enfermagem da NANDA - I define o diagnóstico de enfermagem de Tensão de papel do cuidador como "Dificuldade para atender a responsabilidades, expectativas e/ou comportamentos de cuidados relacionados à família ou a pessoas significativas". Apresenta 7 (sete) fatores relacionados (FR) no receptor de cuidados, 16 no cuidador, 6 (seis) na relação receptor-cuidador, 11 nas atividades de cuidados, 5 (cinco) no campo dos processos familiares e 8 (oito) na área socioeconômicas. Já nas características definidoras são apresentadas 8 (oito) características na área de atividades de cuidado, 6 (seis), 11 e 4 (quatro) acerca do estado de saúde do cuidador nos âmbitos fisiológico, emocional e socioeconômico, respectivamente; ainda, descreve 3 (três) características na relação do receptor-cuidador e 2 (duas) nos processos familiares. Esse diagnóstico de enfermagem, ainda tem elencados 8 (oito) grupos como população em risco e 6 condições associadas ao receptor de cuidados e 3 (três) no cuidador (NANDA $-\mathrm{I}, 2018)$
Os diagnósticos de enfermagem da NANDA I constituem um conhecimento em construção, necessitando ser utilizado, analisado e validado na prática clínica e em todos os cenários de aplicação da enfermagem, visando contribuir para o seu desenvolvimento e consolidação. É importante analisar os fatores relacionados e as características definidoras já presentes na referida taxonomia, mas também, identificar a ocorrência de outras características definidoras e fatores relacionados que porventura possam se apresentar ao longo das avaliações de saúde da pessoa que é objeto do cuidado da enfermagem.

O diagnóstico de tensão do papel de cuidador precisa ser analisado em diferentes situações clínicas onde possa se apresentar, não apenas para sua consolidação, mas também para que a partir dele estratégias de cuidados possam ser pensadas com foco no cuidador. Assim, torna-se importante o desenvolvimento de diferentes estudos que explorem o uso desse diagnóstico tanto no contexto hospitalar, quanto na comunidade em geral.

Esse estudo teve como objetivo verificar a ocorrência do diagnóstico de enfermagem tensão do papel de cuidador em familiares de pessoas com feridas crônicas residentes no município de Palmas, Tocantins; e ainda, identificar os principais indicadores (fatores relacionados e características definidoras) desse diagnóstico.

\section{MATERIAIS E MÉTODOS}

Trata-se de um estudo descritivo realizado com pessoas que cuidam integralmente de um familiar que possui uma ou mais feridas crônicas, e que residem na zona urbana do município de Palmas, Tocantins. O estudo foi apreciado pelo Comitê de Ética em Pesquisa da Universidade Federal do Tocantins, tendo parecer favorável (Protocolo $\mathrm{n}^{\circ}$. 3.095.920/2019). 
A seleção da amostra foi realizada por meio da técnica de bola-de-neve (snowball technique). Esta técnica permite a definição de uma amostra por indicações de pessoas que compartilham ou conhecem outras pessoas que possam responder à questão de pesquisa, e termina quando se alcança o objetivo proposto (BIERNACKI; WALDORF, 1981).

Os critérios básicos de inclusão no estudo foram: ser familiar e realizar cuidados domiciliares de uma pessoa com ferida crônica, incluindo os cuidados relacionados a ferida; ter idade maior ou igual a 18 anos; apresentar o diagnóstico de enfermagem de tensão de papel de cuidador; e, aceitar fazer parte do estudo, formalmente, por meio da assinatura do Termo de Consentimento Livre e Esclarecido. Foram excluídos os cuidadores de pessoas com feridas crônicas que após avaliação de enfermagem, não apresentaram o diagnóstico de enfermagem de tensão de papel de cuidador.

A coleta de dados foi realizada por meio de entrevista semiestruturada, com auxílio de um roteiro de coleta elaborado para esse estudo, sendo composto de questões sócio demográficas do cuidador (idade, sexo, estado civil, escolaridade, ocupação/trabalho, renda familiar, grau de parentesco com a pessoa receptora dos cuidados), e questões referentes ao processo de cuidar (tempo em que o familiar está com essa ferida; tempo em que a pessoa assumiu os cuidados com o familiar; significados e desafios de ser cuidador de um familiar com ferida crônica; se houve mudanças na rotina de atividades diárias, como emprego ou estudo por exemplo; se a condição de ser cuidador afetou a situação econômica da família e, se sim, de que forma; se enfrentou alguma alteração no seu estado de saúde, físico e emocional, após assumir os cuidados; se houve mudança no relacionamento familiar).

As questões norteadoras das entrevistas tiveram como objetivo principal identificar a ocorrência do diagnóstico "tensão no papel de cuidador", bem como seus indicadores, ou seja, os fatores relacionados e as características definidoras, de acordo com o NANDA - I (2018).

A coleta de dados foi realizada na residência dos participantes, em horário previamente agendado, e em ambiente que permitiu a privacidade. As entrevistas foram gravadas e, posteriormente, transcritas na íntegra, visando à fidedignidade das falas.

A análise de dados sócio demográficos foi realizada por meio de estatística descritiva. A análise dos dados qualitativos, que visou a identificação da ocorrência do diagnóstico de enfermagem tensão no papel de cuidador, foi realizada por meio de "agrupamento de dados" e "interpretação do agrupamento" descrito por Craven e Hirnle (2006). Os dados coletados foram agrupados em categorias, visando facilitar o processo de análise e síntese, que culminou na identificação diagnóstica.

\section{RESULTADOS E DISCUSSÃO}

Foram entrevistadas 13 pessoas que realizavam cuidados domiciliares à um familiar com ferida crônica; todavia, a avaliação de enfermagem inicial revelou que destes, somente seis (6) cuidadores tinham o diagnóstico de enfermagem tensão no papel de cuidador. Dessa forma, atendendo aos critérios de inclusão e exclusão para o referido estudo, fizeram parte do corpus de análise final apenas os dados dos seis participantes que possuíam o diagnóstico de enfermagem tensão no papel de cuidador.

Em relação às variáveis sócio demográficas investigadas: sexo do cuidador - dois cuidadores $(33,3 \%)$ eram homens e quatro $(66,6 \%)$ eram mulheres; estado civil do cuidador - dois $(33,3 \%)$ eram solteiros e quatro $(66,6 \%)$ casados/união estável; escolaridade do cuidador - um (16,6\%) analfabeto, um $(16,6 \%)$ possui ensino fundamental completo, três 
(50\%) possuem ensino médio incompleto, um (16,6\%) possui ensino médio completo; renda familiar mensal - quatro $(66,6 \%)$ famílias vivem com dois a quatro salários mínimos, e duas $(33,3 \%)$ famílias vivem com menos de 2 salários mínimos.

Os resultados acerca do gênero do cuidador revelam que, embora haja a inserção da figura masculina no cenário do cuidado domiciliar, este continua sendo predominantemente vinculado às mulheres; sendo evidenciado na literatura especializada (FLORIANO et al. 2012; KRMPOTIC; DE LESO, 2010; PEREIRA; DUQUE, 2017).

Ao investigar a relação do vínculo parental entre cuidador e receptor do cuidado, foi identificado que duas $(33,3 \%)$ pessoas cuidam de seus respectivos pais; uma $(16,6 \%)$ pessoa cuida de sua avó; duas (33,3\%) pessoas cuidam de seus respectivos cônjuges; e uma $(16,6 \%)$ pessoa cuida de sua sogra. Diferentes estudos que investigaram o papel do familiar como um provedor de cuidados de saúde em domicílio, também salientam a importante contribuição de filhos e cônjuges, assim como sua representatividade (CARVALHO; NERY, 2019; EUZEBIO; RABINOVICH, 2006; FLORIANO et al., 2012). Assim, parece haver, socialmente, uma norma "implícita segundo a qual cabe aos filhos e aos cônjuges" o cuidado com seus familiares (AREOSA et $a l, 2014)$.

A pouca escolaridade dos cuidadores, assim como a baixa renda familiar, também foram identificadas entre cuidadores familiares nos estudos de Pereira e Duque (2017) e Silva et al. (2019), evidenciando uma vulnerabilidade das famílias. A situação de vulnerabilidade foi expressa nas falas de alguns cuidadores, e apresentada como indicador do diagnóstico de enfermagem, à saber, o fator relacionado "crise financeira (população de risco)".

Quanto ao tempo em que o cuidador está responsável pelos cuidados com o familiar, incluindo o cuidado especificamente com a (s) ferida (s), este foi de três meses $(16,6 \%)$, um ano $(16,6 \%)$, três anos $(16,6 \%)$, cinco anos (33,3\%), e nove anos (16,6\%). O presente estudo não teve como objetivo analisar o fator tempo e sua relação com o diagnóstico de enfermagem tensão no papel de cuidador, mas, tão somente caracterizar os participantes para melhor compreensão de sua situação de cuidado. Todavia, estudos devem ser realizados visando aprofundar essa visão, uma vez que há estudos que apontam diferenças de entre impactos relacionados ao tempo de cuidado. Duque e Pereira (2017) identificaram que os cuidadores familiares que assumiram essa atribuição há menos de 4 anos, tiveram maior nível de sobrecarga do que aqueles que desempenharam o cuidado há mais de 4 anos.

Quanto ao objetivo principal do presente estudo, de verificar a ocorrência do diagnóstico de enfermagem de tensão do papel de cuidador, a análise de dados, considerando o raciocínio clínico diagnóstico em enfermagem, identificou a ocorrência do referido diagnóstico em 6 cuidadores.

As declarações diagnósticas, foram descritas considerando o padrão de escrita de diagnósticos de Enfermagem segundo a Taxonomia NANDA-I (2018), com seus respectivos indicadores. Estas são apresentadas na Tabela 1.

Tabela 1. Declaração Diagnóstica de Enfermagem do cuidador segundo a Taxonomia NANDA- I.

\section{Cuidador Diagnóstico de Enfermagem}

Cuidador 1 Tensão no papel de cuidador, relacionado a excesso de atividades de cuidado (atividade de cuidado) e dependência (no receptor de cuidados), responsabilidade de cuidados 24 horas por dia (atividade de cuidado). Evidenciado por preocupação com a rotina de cuidados (atividade de cuidado), falta de tempo para atender às 
necessidades pessoais (estado de saúde do cuidador:socioeconômicas).

Cuidador 2 Tensão no papel de cuidador relacionado a resiliência emocional insuficiente (no cuidador), estratégias de enfrentamento ineficazes (no cuidador), excesso de atividades de cuidado (atividade de cuidado), necessidade de cuidado por longo prazo (atividade de cuidado). Evidenciado por depressão (estado de saúde do cuidador: emocionais), falta de tempo para atender às necessidades pessoais (estado de saúde do cuidador: emocionais), dificuldade em ver o receptor de cuidados com a doenças (estado de saúde do cuidador: socioeconômicas), preocupação com as rotinas de cuidados (processos familiares).

Cuidador 3 Tensão no papel de cuidador relacionado a dependência (no receptor de cuidados), condições físicas (no cuidador), necessidade de cuidados por longo prazo (atividade de cuidados), excesso de atividades de cuidados (atividade de cuidados), prejuízo à saúde (condições associadas: no cuidador), e crise financeira (população em risco). Evidenciado por preocupação com a rotina de cuidados (atividade de cuidado), impaciência (estado de saúde do cuidador: emocionais), nervosismo (estado de saúde do cuidador: emocionais), depressão (estado de saúde do cuidador: emocionais), falta de tempo para atender as necessidades pessoais (estado de saúde do cuidador: emocionais), estratégias de enfrentamento ineficazes (estado de saúde do cuidador: socioeconômicas).

Cuidador 4 Tensão no papel do cuidador relacionado a isolamento da família (processos familiares), apoio social insuficiente (socioeconômicos), estressores (no cuidador), excesso de atividades de cuidados (atividades de cuidado). Evidenciado por falta de tempo para atender às necessidades pessoais (estado de saúde do cuidador: emocionais), dificuldades em ver o receptor de cuidados com a doença (relacionamento cuidador-receptor de cuidados).

Cuidador 5 Tensão no papel de cuidador relacionado a condições físicas (no cuidador), responsabilidade de cuidados $24 \mathrm{~h}$ por dia (atividade de cuidado), prejuízo à saúde (condição associada), cuidador é o parceiro (população em risco), crise financeira (população em risco). Evidenciado por preocupação com a rotina de cuidados (atividades de cuidados), somatização (estado de saúde do cuidador: emocionais), dor osteomuscular (física), baixa produtividade no trabalho (estado de saúde do cuidador: socioeconômicas).

Cuidador 6 Tensão no papel de cuidador relacionado a adaptação ineficaz da família (processos familiares), padrão de enfrentamento familiar ineficaz (processos familiares), padrão de relacionamentos ineficazes (relação cuidador-receptor de cuidados), privacidade insuficiente (no cuidador), crise financeira (população de risco), condição do receptor de cuidados inibe o diálogo (população de risco), prejuízo à saúde (condições associadas, no cuidador). Evidenciado por estratégias de enfrentamento ineficazes, nervosismo, impaciência, depressão, falta de tempo para atender às necessidades pessoais (estado de saúde do cuidador: emocionais), conflito familiar (processos familiares).

Fonte: Banco de dados dos autores (2019).

Nas Tabelas 2 e 3 são apresentadas a distribuição dos fatores relacionados e a frequência das características definidoras indicativas do diagnóstico de Enfermagem tensão de papel de cuidador em familiares de pessoas com feridas crônicas de acordo com a declaração diagnóstica. Observou-se que os principais fatores relacionados (Tabela 1) ao DE tensão no papel de cuidador foram o excesso de 
atividades de cuidado (atividade de cuidado), a crise financeira (população em risco) e o prejuízo à saúde (condições associadas: no cuidador).

Tabela 2. Distribuição dos fatores relacionados ao diagnóstico de Enfermagem tensão no papel de cuidador em familiares de pessoas com feridas crônicas, Palmas, Tocantins, 2019 (n=6).

\begin{tabular}{|c|c|c|}
\hline Fatores Relacionados & $\mathbf{n}$ & $\%$ \\
\hline $\begin{array}{l}\text { Excesso de atividades de cuidado } \\
\text { (atividade de cuidado) }\end{array}$ & 4 & 66,6 \\
\hline $\begin{array}{l}\text { Crise financeira } \\
\text { (população em risco) }\end{array}$ & 3 & 50,0 \\
\hline $\begin{array}{l}\text { Prejuízo à saúde } \\
\text { (condições associadas: no cuidador) }\end{array}$ & 3 & 50,0 \\
\hline $\begin{array}{l}\text { Dependência } \\
\text { (no receptor de cuidados) }\end{array}$ & 2 & 33,3 \\
\hline $\begin{array}{l}\text { Condições físicas } \\
\text { (no cuidador) }\end{array}$ & 2 & 33,3 \\
\hline $\begin{array}{l}\text { Necessidade de cuidado por longo } \\
\text { prazo (atividade de cuidado) }\end{array}$ & 2 & 33,3 \\
\hline $\begin{array}{l}\text { Responsabilidade de cuidados } 24 \\
\text { horas por dia (atividade de cuidado) }\end{array}$ & 2 & 33,3 \\
\hline $\begin{array}{l}\text { Adaptação ineficaz da família } \\
\text { (processos familiares) }\end{array}$ & 1 & 16,6 \\
\hline $\begin{array}{l}\text { Apoio social } \\
(\text { socioeconômicos) }\end{array}$ & 1 & 16,6 \\
\hline $\begin{array}{l}\text { Condição do receptor de cuidados } \\
\text { inibe o diálogo (população de risco) }\end{array}$ & 1 & 16,6 \\
\hline $\begin{array}{l}\text { Estratégias de enfrentamento } \\
\text { ineficazes (no cuidador) }\end{array}$ & 1 & 16,6 \\
\hline Estressores (no cuidador) & 1 & 16,6 \\
\hline $\begin{array}{l}\text { Isolamento da família (processos } \\
\text { familiares) }\end{array}$ & 1 & 16,6 \\
\hline $\begin{array}{l}\text { Padrão de enfrentamento familiar } \\
\text { ineficaz (processos familiares) }\end{array}$ & 1 & 16,6 \\
\hline $\begin{array}{l}\text { Padrão de relacionamentos ineficazes } \\
\text { (relação cuidador-receptor de } \\
\text { cuidados) }\end{array}$ & 1 & 16,6 \\
\hline $\begin{array}{l}\text { Privacidade insuficiente } \\
\text { (no cuidador) }\end{array}$ & 1 & 16,6 \\
\hline $\begin{array}{l}\text { Resiliência emocional insuficiente (no } \\
\text { cuidador) }\end{array}$ & 1 & 16,6 \\
\hline
\end{tabular}

Fonte: Banco de dados dos autores (2019).

A tensão do papel do cuidador, segundo Silva e Santana (2014), apresenta como principais fatores relacionados à falta de apoio recebido, a dependência e a dificuldade relacionada a recursos financeiros insuficientes. Referem ainda que, a sobrecarga de atividades, a insegurança e o despreparo para a realização dos cuidados podem contribuir para problemas de saúde no cuidador, a longo prazo.

É certo que tais fatores não podem ser vistos isoladamente, ainda que não relatados em conjunto ou a um só tempo por todos os cuidadores. Desvios de saúde crônicos geram demandas de cuidados que representam tanto um impacto financeiro às famílias, quanto ao tempo do cuidador devido às atividades de cuidados. Com o passar dos meses ou anos, esse impacto pode gerar respostas humanas negativas no cuidador e na família como um todo, caso esses fatores não sejam gerenciados adequadamente.

A consequência da dificuldade de adaptação à situação de cuidar de um familiar com ferida crônica pode ser expressa na "falta de tempo para atender às necessidades pessoais" do cuidador, sendo identificado no presente estudo como principal característica definidora do DE tensão do papel de cuidador (Tabela 3).

Tabela 3. Frequência das características definidoras indicativas do diagnóstico de Enfermagem tensão de papel de cuidador em familiares de pessoas com feridas crônicas, Palmas, Tocantins, 2019 ( $n=6)$.

\begin{tabular}{llc}
\hline Características Definidoras & n & $\%$ \\
\hline $\begin{array}{l}\text { Falta de tempo para atender às necessidades } \\
\text { pessoais (estado de saúde do cuidador: } \\
\text { socioeconômicas) }\end{array}$ & 83,3 \\
\end{tabular}

Preocupação com a rotina de cuidados $4 \quad 66,6$ (atividade de cuidado) 
Depressão (estado de saúde do cuidador: 3 50,0 emocionais)

Dificuldade em ver o receptor de cuidados $2 \quad 33,3$ com a doenças (estado de saúde do cuidador: socioeconômicas)

Estratégias de enfrentamento ineficazes 2 33,3 (estado de saúde do cuidador: socioeconômicas)

Impaciência (estado de saúde do cuidador: 2 33,3 emocionais)

Nervosismo (estado de saúde do cuidador: 2 33,3 emocionais)

Baixa produtividade no trabalho (estado de $1 \quad 16,6$ saúde do cuidador: socioeconômicas)

Condição do receptor de cuidados inibe o $1 \quad 16,6$ diálogo (população de risco)

Dor osteomuscular (física)

$1 \quad 16,6$

Somatização

$1 \quad 16,6$

Fonte: Banco de dados dos autores (2019).

Essa característica definidora por si só também pode estar associada a outras características definidoras, que se manifestam tanto na situação de saúde (físicas e emocionais) do cuidador, até reflexos na sua vida laboral, com baixa produtividade no trabalho ou mesmo afastamentos do trabalho para se dedicar exclusivamente aos cuidados com seu familiar.

O cuidador familiar possui atividades complexas e voluntárias que podem envolver sentimentos contraditórios e diversos, tais como raiva, culpa, medo, confusão, cansaço, estresse, tristeza, nervosismo. Esses sentimentos podem ser apresentados simultaneamente e devem ser compreendidos, e fazem parte da relação entre o cuidador e a pessoa cuidada (DINIZ; LIMA; SILVA, 2017). Tais características podem apresentar prejuízos a saúde do cuidador quando as estratégias de enfrentamento são ineficazes, assim como quando esses sentimentos perduram por um longo período. Em vista disso, os profissionais devem estar atentos para assistir não somente quem demanda cuidados, mas também quem cuida.

Certamente que os problemas sociais são complexos, e exigem a formulação de estratégias de apoio social por parte dos governantes do País/ Estados/ Municípios. Todavia, é necessário que os profissionais que estão mais próximos da população (re) pensem estratégias de atenção em saúde que sejam possíveis na realidade de trabalho de cada um, (re)inventando sua prática cotidianamente, buscando sistemas de apoio factíveis, que visem melhorar a saúde da população.

O uso de ferramentas de trabalho que direcionam à prática de enfermagem sistematizada, favorece o processo de pensamento crítico em enfermagem, bem como a tomada de decisão. Nesse sentido, o uso do processo de enfermagem pode contribuir significativamente, por meio da avaliação intencional, sistematizada e direcionada, para a possibilidade do processo de julgamento clínico e identificação diagnóstica mais assertivos, contribuindo para um planejamento da assistência de enfermagem que melhor atenda às demandas do receptor de cuidados.

\section{CONCLUSÃO}

Os resultados deste estudo evidenciam a ocorrência do diagnóstico de enfermagem tensão do papel de cuidador como um importante problema vivenciado entre cuidadores de familiares com feridas crônicas, e alertam para a necessidade de um olhar atento às famílias de pessoas com feridas crônicas em cuidados domiciliares.

Importante observar a relação entre os indicadores diagnósticos identificados, pois há uma relação direta entre eles e que reforçam a necessidade de avaliação global do cuidador. A enfermagem deve ter esse olhar holístico não apenas para a pessoa que é a fonte primária do cuidado, no caso a pessoa com 
ferida, mas esse olhar precisa ser ampliado, de maneira a também atender o seu cuidador familiar.

\section{AGRADECIMENTO}

Agradecemos às famílias que contribuíram para o desenvolvimento desse estudo, nos recebendo gentilmente e compartilhando conosco um pouco de sua experiência de vida como cuidadores de pessoas com feridas. Que o presente estudo possa contribuir no processo de reflexão acerca do cuidado de enfermagem às pessoas com feridas em domicílio e seus familiares, e que seja manifesto em atenção integral à comunidade.

Todos os autores declararam não haver qualquer potencial conflito de interesses referente a este artigo.

\section{REFERÊNCIAS}

AREOSA, S. V. C.; HENZ, L. F.; LAWISCH, D.; AREOSA, R. C. Cuidar de si e do outro: estudo sobre os cuidadores de idosos. Psic., Saúde \& Doenças, Lisboa, v. 15, n. 2, p. 482-494, 2014.

BIERNACKI, P.; WALDFORD, D. Snowball Sampling: Problems and Techniques of Chain Referral Sampling. Sociol Methods Res., n. 2, p. 141-163, 1981.

CARVALHO, Elcyana Bezerra; NERI, Anita Liberalesso. Padrões de uso do tempo em cuidadores familiares de idosos com demências. Rev. bras. geriatr. gerontol., v. 22, n. 1, e180143, 2019.

CRAVEN, R. E.; HIRNLE, C. J. Fundamentos de Enfermagem: Saúde e Função Humanas, $4^{\mathrm{a}}$ Ed. Rio de Janeiro: Guanabara Koogan, 2006.

DINIZ, A. S. S.; LIMA, R. A.; SILVA, B.R.S. Sobrecarga do cuidador de idoso: uma revisão integrativa. Rev Pesq Saúde, v.18, n.3, p. 184-188, 2017.

EUZEBIO, C. J. V.; RABINOVICH, E. P. Compreendendo o cuidador familiar do paciente com sequela de Acidente Vascular Encefálico. Temas psicol., Ribeirão Preto, v.14, n.1, p.63-79, 2006.

FLORIANO, L. A.; AZEVEDO, R. C. S.; REINERS, A. A. O.; SUDRÉ, M. R. S. Cuidado realizado pelo cuidador familiar ao idoso dependente, em domicílio, no contexto da estratégia de Saúde da Família. Texto contexto - enferm., v. 21, n. 3, p. 543-548, 2012.

HICKMAN, J. S. Introdução à teoria da Enfermagem. In: GEORGES, J. Teorias de Enfermagem: os fundamentos da prática profissional. $4^{\mathrm{a}}$ ed. Porto Alegre: Artmed Ed. 2000.

KRMPOTIC, C. S.; DE LESO, L. C. Los cuidados familiares: aspectos de la reproducción social a la luz de la desigualdad de género. Rev. Katálysis, v.13, n.1, p. 95-101, 2010.

LEAL, T. S.; OLIVEIRA, B. G.; BOMFIM, E. S.; FIGUEIREDO, N. L.; SOUZA, A. S. S.; SANTOS, I. S. C. S. Percepção de pessoas com a ferida crônica. Rev enferm UFPE online., Recife, v. 11, n. 3, p.11561162, 2017.

MONTEFUSCO, S. R. A; BACHION, M. M.; VERA, I.; CAIXETA, C.; MUNARI, D. B. Tensão do papel de cuidador: ocorrência em familiares de pessoas com doenças crônicas hospitalizadas. CiencCuidSaude, v.10, n. 4, p. 828-835, 2011.

NANDA - I. HERDMAN, T. H.; KAMITSURU, S. (Org.). Diagnósticos de Enfermagem da NANDA International: Definições e Classificação 20182020. $11^{\mathrm{a}}$ ed. Porto Alegre: Artmed, 2018.

PEIXOTO, M. J.; BORGES, E. O sofrimento no contexto da doença. Revista Portuguesa de Enfermagem de Saúde Mental, Porto, n. 6, p. 36-39, 2011.

PEREIRA, S.; DUQUE, E. Cuidar de Idosos Dependentes - A Sobrecarga dos Cuidadores Familiares. Revista Kairós - Gerontologia, v. 20, n.1, p. 187-202, 2017.

SILVA, M. S.; BEUTER, M.; BENETTI, E. R. R.; BRUINSMA, E. R.; DONATI, L.; GIRARDONPERLINI, N. M. O. Situações vivenciadas por cuidadores familiares de idosos na atenção domiciliar. Revista de Enfermagem da UFSM, v. 9, n. e10, p121, 2019.

SILVA, R. M. F. M.; SANTANA, R. F. Diagnóstico de enfermagem "tensão do papel de cuidador": revisão Integrative. Rev. Bras. Geriatr. Gerontol., Rio de Janeiro, v. 17, n. 4, p. 887-896, 2014. 